\title{
Global Evaluation of the ISBA-TRIP Continental Hydrological System. Part II: Uncertainties in River Routing Simulation Related to Flow Velocity and Groundwater Storage
}

\author{
B. Decharme, R. Alkama, And H. Douville \\ CNRM-GAME, Météo-France, and CNRS, Toulouse, France \\ M. Becker AND A. CAZENAVE \\ CNRS/CNES/Université Toulouse 3, LEGOS/GOHS, Toulouse, France
}

(Manuscript received 27 August 2009, in final form 12 January 2010)

\begin{abstract}
In the companion paper to this one (Part I), the Interactions between Soil, Biosphere, and Atmosphere-Total Runoff Integrating Pathways (ISBA-TRIP) continental hydrological system of the Centre National de Recherches Météorologiques is evaluated by using river discharge measurements and terrestrial water storage (TWS) variations derived from three independent datasets of the Gravity Recovery and Climate Experiment (GRACE). One of the conclusions is that the river reservoir simulated by TRIP at the global scale seems to be one of the main sources of TWS and/or discharge errors. Here, the authors study these uncertainties in river routing processes, such as flow velocity and groundwater storage. For this purpose, a simple groundwater reservoir depending on a time delay factor and a variable streamflow velocity calculated via Manning's formula are added to TRIP following the approach of Arora and Boer. The previous and the new TRIP are then compared, and two studies of the sensitivity to the groundwater time delay factor and to the flow velocity are performed. Using the same experiment design as in Part I, the authors show that the effect of this flow velocity and of the groundwater time delay factor on the ISBA-TRIP simulation is potentially significant. Nevertheless, over tropical and temperate basins, a competition between the two processes implies a slight difference between the previous and the new TRIP compared to both the GRACE and the discharge signals. The global results underline that simulating a realistic streamflow velocity is a key process for globalscale application.
\end{abstract}

\section{Introduction}

Continental hydrological systems (CHSs), composed of land surface models (LSMs) and river routing models (RRMs), provide lower boundary conditions on temperature and moisture in atmospheric general circulation models (AGCMs) and simulate river discharges over the entire globe. RRMs have been introduced into earth system models (ESMs) to convert the runoff simulated by LSMs into river discharge to transfer the continental freshwater into the oceans and then to close the global hydrological cycle. RRM simulations are not negligible in global climate modeling for at least three reasons.

Corresponding author address: Bertrand Decharme, CNRMGAME, Météo-France, and CNRS, URA 1357, 42 av. Gaspard Coriolis, 31057 Toulouse, France.

E-mail: bertrand.decharme@cnrm.meteo.fr
First, human society is drastically dependent on continental hydrological processes. Rivers and lakes provide water for industry, agriculture, and household use. The future increase in population in relation to the water availability evolution due to global climatic changes may drastically stress terrestrial water resources. Second, such resources could have an effect on the thermohaline circulation simulated by ocean general circulation models (OGCMs) through the influence of continental freshwater on the ocean salinity at the mouth of the largest rivers and/or on the northern sea ice seasonal refreezing (Broecker et al. 1990; Sausen et al. 1994). Third, RRMs allow direct evaluation of AGCM-LSM simulations via the comparison of simulated discharges with in situ measurements. If ESMs become important tools in determining global policy (Pachauri and Reisinger 2007), AGCMs, LSMs, and RRMs must be tested against a maximum of constrains. 
Generally, these evaluations are essentially made by comparison with streamflow data gauged in situ. Alkama et al. (2010; Part I of this study) provide another constraint for evaluating the Interactions between Soil, Biosphere, and Atmosphere Total Runoff Integrating Pathways (ISBA-TRIP) CHS of the Centre National de Recherches Météorologique (CNRM) via a comparison with three gravity fields of the Gravity Recovery and Climate Experiment (GRACE) that estimate terrestrial water storage (TWS) variations. The main results show that ISBATRIP captures the seasonal and interannual variability in both TWS and streamflow. Nevertheless, an underestimation of continental evaporation seems to be an important source of error, mainly due to the nonrepresentation of marshes, ponds, irrigation, and flooding. Furthermore, the amplitude of the simulated TWS is generally larger than GRACE estimates over tropical regions, while a lag between simulated and observed discharges is found for some Siberian rivers. Comparing global hydrological simulations with and without the TRIP RRM, Kim et al. (2009) have shown that neglecting river storage may lead to a mismatch in the amplitude and phase of TWS seasonal variations compared to the GRACE observations. With the ISBA-TRIP CHS, Part I shows that error on TWS amplitude and phase can remain high and could be linked to river routing processes, such as flow velocity, dams, irrigation, or groundwater storage.

The goal of the present study is not to solve all the issues raised by Part I but to point out the part of uncertainty in river routing processes simulated by TRIP related to flow velocity and groundwater storage. This is done via comparison with the GRACE TWS estimate and with discharge measurements. In other words, is the representation of flow velocity and groundwater storage important at global scale? Another important issue is whether GRACE can help climatologists to evaluate RRM processes, such as groundwater flow contribution and/or streamflow velocity at global scale. The simplicity of TRIP does not allow these objectives to be dealt with; therefore, a simple groundwater reservoir is added to TRIP, following Arora and Boer (1999). This parameterization does not represent the groundwater dynamics but only the delays the groundwater flow contribution to the river streamflow. To evaluate the effect of the river flow velocity, Arora and Boer's (1999) variable velocity scheme is introduced into the TRIP framework in which the velocity is computed by means of Manning's formula, using the water depth related to the stream water mass. These developments are briefly presented in section 2. The experimental design, together with the data used, is described in section 3. A comparison between the previous and new TRIP is given in section 4 and a study of the sensitivity to the groundwater flow contribution time delay factor and to surface flow velocity values are reported in section 5. Finally, the results are discussed and the main conclusions are drawn in section 6 .

\section{TRIP overview}

As previously explained in Part I, the TRIP RRM was developed by Oki and Sud (1998) at the University of Tokyo. It is used at Météo-France to convert the simulated runoff into river discharge using a global river channel network at $1^{\circ}$ resolution. The original TRIP model is based on a single prognostic reservoir whose discharge $Q_{\text {out }}^{S}\left(\mathrm{~kg} \mathrm{~s}^{-1}\right)$ is linearly related to the river mass $S(\mathrm{~kg})$ using a uniform and constant flow velocity $v\left(\mathrm{~m} \mathrm{~s}^{-1}\right)$ equal to $0.5 \mathrm{~m} \mathrm{~s}^{-1}$ :

$$
\frac{\partial S}{\partial t}=Q_{\mathrm{in}}^{S}+Q_{\mathrm{sb}}-Q_{\mathrm{out}}^{S}, \quad \text { where } \quad Q_{\mathrm{out}}^{S}=\frac{v}{L} S,
$$

$Q_{\mathrm{in}}^{S}\left(\mathrm{~kg} \mathrm{~s}^{-1}\right)$ represents the sum of the surface runoff from ISBA within the grid cell and the water inflow from the adjacent upstream neighboring grid cells, $Q_{\mathrm{sb}}\left(\mathrm{kg} \mathrm{s}^{-1}\right)$ is the deep drainage from ISBA, and $L(\mathrm{~m})$ is the river length, which takes into account a meandering ratio of 1.4 as proposed by Oki and Sud (1998). This configuration corresponds to the control experiment, named CTL, used in this study and performed in Part I.

To assess groundwater uncertainties, a simple groundwater reservoir was added to TRIP (Arora and Boer 1999). The TRIP model is now based on two prognostic equations, the groundwater outflow of which is linearly related to the groundwater mass $G(\mathrm{~kg})$, through a uniform, constant time delay factor $\tau(\mathrm{s})$ :

$$
\mid \begin{aligned}
& \frac{\partial G}{\partial t}=Q_{\mathrm{sb}}-\frac{G}{\tau} \\
& \frac{\partial S}{\partial t}=Q_{\mathrm{in}}^{S}+\frac{G}{\tau}-\frac{v}{L} S
\end{aligned} .
$$

Equation (2) shows that $G$ does not represent the groundwater dynamics, but only delays the groundwater flow contribution to the surface river reservoir within a particular grid cell: the deep drainage is fed into the surface reservoir with a time delay factor of $\tau$ compared to Eq. (1). In previous studies, the value of $\tau$ varies from 10 to 60 days, depending on soil texture characteristics (Arora and Boer 1999; Lucas-Picher et al. 2003). This methodology is debatable because the geology also plays an important role (Fan et al. 2007). Arora et al. (1999), using daily hydrograph data, showed that $\tau$ can be approximately evaluated at 30 days over the Mississippi basin and 60 days over the Amazon. Over the Illinois, one of the few regions where 
long-term groundwater level measurements have been recorded, Brutsaert (2008) has made a base flow analysis that confirms that the time delay factor for large basins of this type is of the order of $45 \pm 15$ days. In this study, we chose to fix $\tau$ globally at 30 days and a sensitivity study to this factor is given in section 5 .

To assess the effect of the river flow velocity on simulated TWS and discharges, the variable streamflow velocity scheme from Arora and Boer (1999) was introduced into TRIP. This formalism is based on Manning's formula:

$$
v=\frac{\kappa}{n} R^{2 / 3} s^{1 / 2}
$$

where $s\left(\mathrm{~m} \mathrm{~m}^{-1}\right)$ is the downstream river height loss per unit length approximated as the river bed slope, $\kappa\left(\mathrm{m}^{-3} \mathrm{~s}^{-1}\right)$ is a conversion constant equal to $1 \mathrm{~m}^{-3} \mathrm{~s}^{-1}$, $n$ is the dimensionless Manning friction factor, and $R(\mathrm{~m})$ is the hydraulic radius. As in Arora and Boer (1999), a rectangular river cross section is assumed for the calculation of $R$ in each grid cell, depending on the water height of the stream reservoir $h_{s}(\mathrm{~m})$ :

$$
R=\frac{W h_{s}}{W+2 h_{s}}, \quad \text { where } \quad h_{s}=\frac{S}{L W \rho_{w}},
$$

where $\rho_{w}\left(\mathrm{~kg} \mathrm{~m}^{-3}\right)$ is the water density and $W(\mathrm{~m})$ is the stream river width. More details on the estimation of this stream river width can be found in the next section. When the variable streamflow velocity scheme is used, Eq. (2) is solved with a "Runge-Kutta order 4" method to prevent numerical bias given by the nonlinearity of Manning's formula [Eqs. (3) and (4)].

A schematic representation of the new TRIP version is given in Fig. 1. Note that, over high-latitude regions, groundwater is not simulated because the presence of permafrost generally inhibits the development of deep water storage. In the ISBA simulation, the permafrost is not represented and a mask is applied in TRIP to prevent the development of groundwater over permafrost regions. This permafrost map, shown in Fig. 2, was provided by the National Snow and Ice Data Center (NSIDC) at $0.5^{\circ} \times 0.5^{\circ}$ resolution (Brown et al. 1998) and interpolated on to a $1^{\circ} \times 1^{\circ}$ grid for this study.

\section{Experimental design}

\section{a. Experiment}

First, an offline hydrological simulation with the new TRIP (groundwater + variable flow velocity), named $\mathrm{Vv}$, was compared to the CTL experiment performed in Part I. Every day, the total runoff (surface runoff + deep

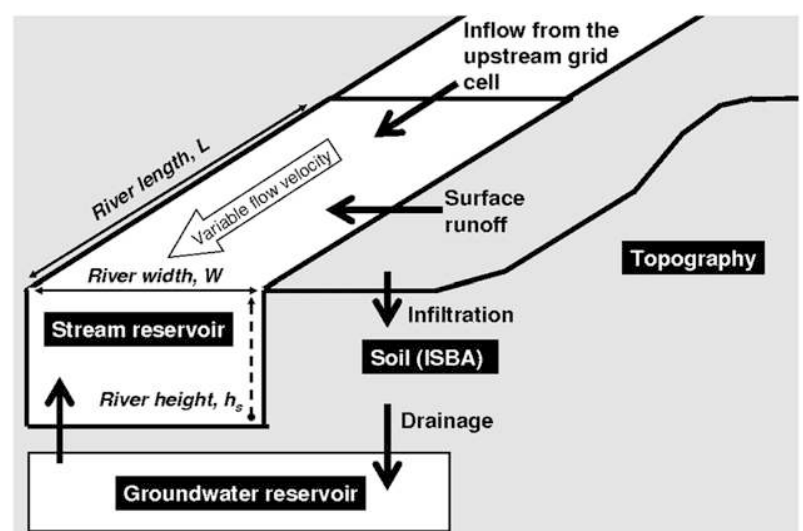

FIG. 1. Schematic representation of the new TRIP version. The surface runoff and the deep drainage from ISBA flow into the stream and the groundwater reservoirs, respectively. The water inflow from the adjacent upstream neighboring grid cell also contributes to the stream reservoir. The stream reservoir has a rectangular geometry given by $L, W$, and $h_{s}$. These three parameters are then used to compute a variable velocity in the grid cell. More details can be found in section 2 .

drainage) simulated by ISBA from Part I was fed into TRIP. TRIP was integrated at $1^{\circ}$ resolution with a 1 -h time step for the whole period of 1983-2006, the first three years being applied as spinup. Therefore, only the years 1986-2006 were used in the evaluation stage.

Second, two sensitivity studies were performed with respect to the groundwater time delay factor $\tau$ and to the streamflow velocity $v$. Four additional simulations were performed with a constant velocity equal to $0.5 \mathrm{~m} \mathrm{~s}^{-1}$ and different $\tau(10,30,60$, and 120 days). Four other simulations were done using $\tau$ fixed at 30 days and different streamflow velocities $\left(0.25,0.5,1\right.$, and $1.5 \mathrm{~m} \mathrm{~s}^{-1}$; a summary of these sensitivity experiments is given in Table 1).

All simulations were evaluated by comparison with the same data as used by Part I. The simulated smoothed TWS signal was compared to three independent GRACE datasets. The simulated discharges were compared to 93 gauging measurements distributed over the globe (Fig. 2). Only subbasins with drainage areas of at least $10^{5} \mathrm{~km}^{2}$ and with a minimum observation period of four years were used.

\section{b. Specific parameters}

For the $\mathrm{Vv}$ experiment, special attention was paid to the computation of the river bed slope at $1^{\circ} \times 1^{\circ}$ resolution because river slope is a critical parameter for computing velocity via Manning's formula. The Simulated Tropical Network at 30-min spatial resolution (STN-30p) digital elevation model (DEM) provided at $0.5^{\circ} \times 0.5^{\circ}$ resolution by the International Satellite Land 


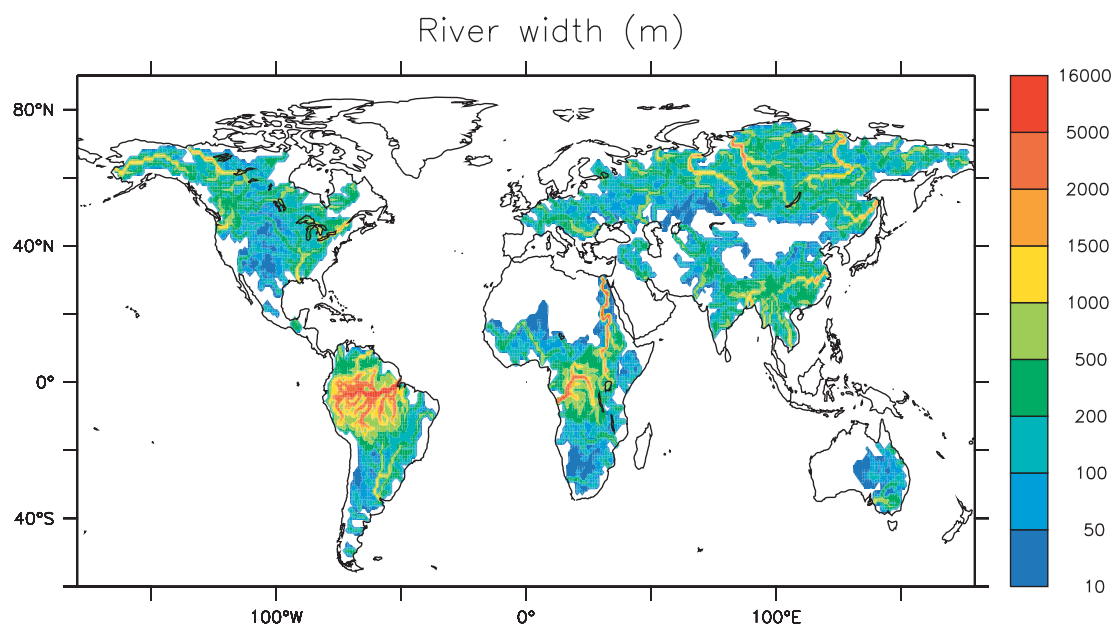

Permafrost regions \& Gauging measurement periods (Years)

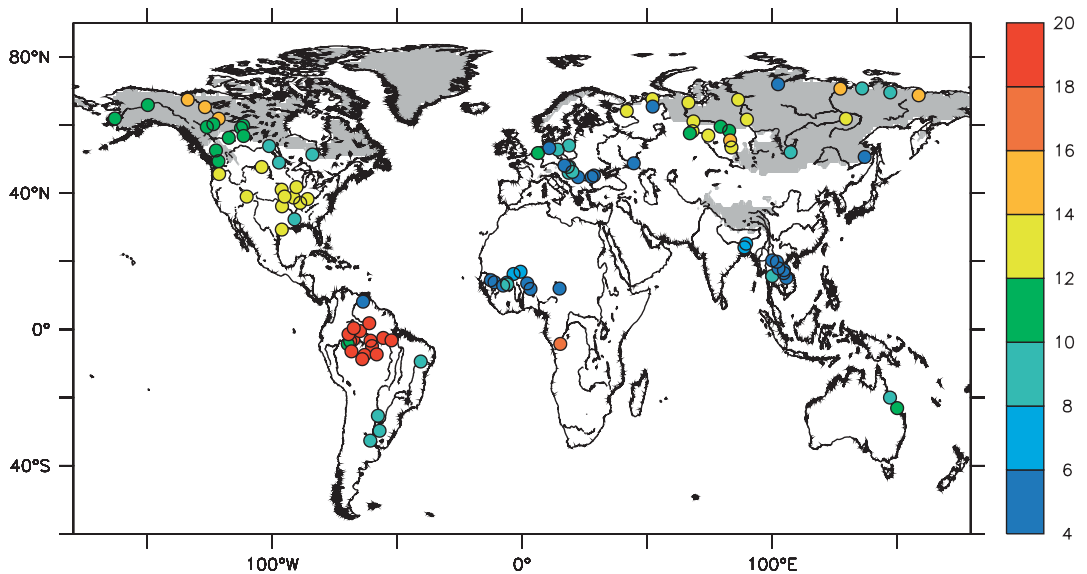

FIG. 2. River width (m) used by the (top) variable flow velocity algorithm and (bottom) location of gauging stations used for the evaluation. Basins not referenced in TRIP appear in white in the top panel. The color of each station represents the period in the year of monthly measurements, beginning in January 1986. The gray area shows the permafrost region where the groundwater parameterization is not used.

Surface Climatology Project, Initiative II (ISLSCP2) database (available online at http://islscp2.sesda.com) was used. The STN-30p DEM was heavily edited to represent the actual elevation along the river network on a global scale, based on the aggregated HYDRO1K DEM at 1-km resolution. Further adjustments were made to eliminate some of the unrealistic rapid slope changes in the STN-30p DEM along the global river network. In this study, the STN-30p DEM was interpolated at $1^{\circ} \times 1^{\circ}$ resolution. Generally, a $1^{\circ}$ grid box is composed of four $0.5^{\circ}$ grid boxes, and a simple interpolation results in the averaging of these four grid boxes according to the area of each $0.5^{\circ}$ grid box. In this study, the major rivers were identified in each of the four $0.5^{\circ}$ grid boxes composing a $1^{\circ}$ grid cell. Next, it was imposed that the number of $0.5^{\circ}$ grid boxes containing the major beds could vary from two to four inside the corresponding $1^{\circ}$ grid cell. The interpolation at $1^{\circ}$ resolution was then carried out using the $0.5^{\circ}$ grid boxes containing the major beds of the river rather than using four $0.5^{\circ}$ grid boxes each time. For example, if one of the four $0.5^{\circ}$ grid boxes represented a mountain while the other three corresponded to the valley where the major river flowed, the interpolation to $1^{\circ}$ resolution was made by averaging only the three $0.5^{\circ}$ grid boxes containing the valley. This approach allowed the elevation along the river to be computed at $1^{\circ}$ resolution with a better accuracy. River bed slopes, $s\left(\mathrm{~m} \mathrm{~m}^{-1}\right)$, were then calculated as follows, using both the elevation and the TRIP flow direction at $1^{\circ} \times 1^{\circ}$ resolution:

$$
s=\max \left(\frac{E-E_{\text {next }}}{L}, 10^{-5}\right)
$$


TABLE 1. Summary of experiments. The CTL experiment is the same as in Part I. The color plot of each experiment for the figures presented in sections 4 and 5 is also given.

\begin{tabular}{|c|c|c|c|c|}
\hline Experiment & Description & $\tau$ (days) & $v\left(\mathrm{~m} \mathrm{~s}^{-1}\right)$ & Color \\
\hline CTL & Control experiment & None & 0.5 & Red \\
\hline Vv & Variable velocity and groundwater schemes & 30 & Vary & Blue \\
\hline GW15 & Groundwater time delay factor sensitivity & 15 & 0.5 & Green \\
\hline GW30 & Groundwater time delay factor sensitivity & 30 & 0.5 & Blue \\
\hline GW60 & Groundwater time delay factor sensitivity & 60 & 0.5 & Brown \\
\hline GW120 & Groundwater time delay factor sensitivity & 120 & 0.5 & Purple \\
\hline V0.25 & Flow velocity sensitivity & 30 & 0.25 & Green \\
\hline V0.5 & Flow velocity sensitivity & 30 & 0.5 & Red \\
\hline V1 & Flow velocity sensitivity & 30 & 1.0 & Brown \\
\hline V1.5 & Flow velocity sensitivity & 30 & 1.5 & Purple \\
\hline
\end{tabular}

where $E(\mathrm{~m})$ is the elevation in the grid cell, $E_{\text {next }}(\mathrm{m})$ is the elevation in the downstream neighboring grid cell, and $L(\mathrm{~m})$ is the river length.

Oki and Sud (1998) compute the river length $L$ assuming earth to be a spheroid in the meridional plane. A length, $l(\mathrm{~m})$, between the grid cell and the downstream neighboring grid cell in the $1^{\circ} \times 1^{\circ}$ network is calculated. Because the presence of a river meanders in the real world, the length $l$ is increase by a meandering ratio of 1.4 and $L=1.4 \times l$. More details can be found in Oki and Sud (1998).

The river width $W$ was estimated over the 183 basins referenced in the TRIP network via a geomorphologic relationship between $W$ and mean annual discharges at each river cross section (Arora and Boer 1999). The estimation of annual mean discharges in each grid cell was given by Cogley's (2003) global runoff database. Here W varied from the river mouth to the upstream grid cells as shown in Fig. 2. Some calculated values and in situ estimations are given in Table 2. Over basins not represented in the TRIP network, a constant flow velocity of $0.5 \mathrm{~m} \mathrm{~s}^{-1}$ was used.

The Manning friction factor varied linearly and proportionally to $W$ from 0.04 near the river mouth to 0.1 in the upstream grid cells. This factor can be defined as the resistance of the bed of a channel to the flow of water in it. The Manning friction factor is then difficult to compute at global scale. It generally varies from 0.03 to 0.04 , for natural streams with deep pools at the river mouth, to $0.1-0.15$ for very small rivers or flood plains (Arora and Boer 1999). Some previous studies have used a global constant value of 0.035 (Arora et al. 1999; Arora and Boer 1999; Lucas-Picher et al. 2003). Since values of $n$ vary in natural streams, the assumption of a global constant roughness coefficient would contain limitations. In this study, the river width of each grid cell from the mouth to the upstream grid cells of each basin was known. It was assumed that upstream grid cells represented the narrower rivers and that the mouths could be seen as a "natural streams with deep pools" in each basin. Because the roughness of the river bed had a greater effect on small river flow than on large mouth flow, a linear relationship was taken between the Manning $n$ and the river width used in each basin:

$$
n=n_{\text {min }}+\left(n_{\text {max }}-n_{\text {min }}\right)\left(\frac{W_{\text {mouth }}-W}{W_{\text {mouth }}-W_{\text {min }}}\right)
$$

where $n$ represents the Manning $n$ factor of the grid cell, $n_{\text {max }}$ and $n_{\text {min }}$ are the maximum and the minimum values of the Manning friction factor, respectively (equal to 0.1 and 0.04 , respectively), $W_{\min }(\mathrm{m})$ is the minimum river

TABLE 2. Major river basin characteristics in the TRIP $1^{\circ} \times 1^{\circ}$ network. The basin name, the drainage area, the locations, and the calculated mean width of each river mouth are shown in the first five columns. Some width estimations, obs width, from diverse sources (Arora and Boer 1999; Kouraev et al. 2004) are shown in the sixth column.

\begin{tabular}{lcrrrc}
\hline \hline \multicolumn{1}{c}{ Basins } & $\begin{array}{c}\text { Area } \\
\left(\mathrm{km}^{2}\right)\end{array}$ & \multicolumn{1}{c}{$\begin{array}{c}\text { Lat } \\
\left({ }^{\circ} \mathrm{N}\right)\end{array}$} & $\begin{array}{c}\text { Lon } \\
\left({ }^{\circ} \mathrm{E}\right)\end{array}$ & $\begin{array}{c}\text { Width } \\
(\mathrm{m})\end{array}$ & $\begin{array}{c}\text { Obs width } \\
(\mathrm{m})\end{array}$ \\
\hline Amazon & 6134937 & 0.5 & -50.5 & 15660 & 15000 \\
Congo & 3751344 & -5.5 & 12.5 & 5352 & \\
Mississippi & 3245654 & 29.5 & -90.5 & 1392 & 1250 \\
Parana & 3007044 & -34.5 & -58.5 & 1422 & \\
Nile & 2961360 & 30.5 & 30.5 & 2715 & \\
Ob & 2958911 & 66.5 & 70.5 & 2083 & 2000 \\
Yenisei & 2603497 & 71.5 & 83.5 & 2577 & 2200 \\
Lena & 2335590 & 73.5 & 124.5 & 1980 & 1600 \\
Niger & 2119052 & 5.5 & 6.5 & 977 & \\
Amur & 1864936 & 53.5 & 140.5 & 1947 & \\
Yangtze & 1827110 & 31.5 & 120.5 & 1903 & \\
Mackenzie & 1736363 & 68.5 & -134.5 & 1714 & 1600 \\
Volga & 1387236 & 46.5 & 48.5 & 922 & \\
Ganges & 1029593 & 22.5 & 88.5 & 1270 & \\
Orinoco & 958945 & 9.5 & -61.5 & 1681 & \\
Yukon & 844111 & 62.5 & -164.5 & 1547 & \\
Danube & 804386 & 45.5 & 29.5 & 1074 & \\
Mekong & 801386 & 10.5 & 106.5 & 1357 & \\
\hline
\end{tabular}



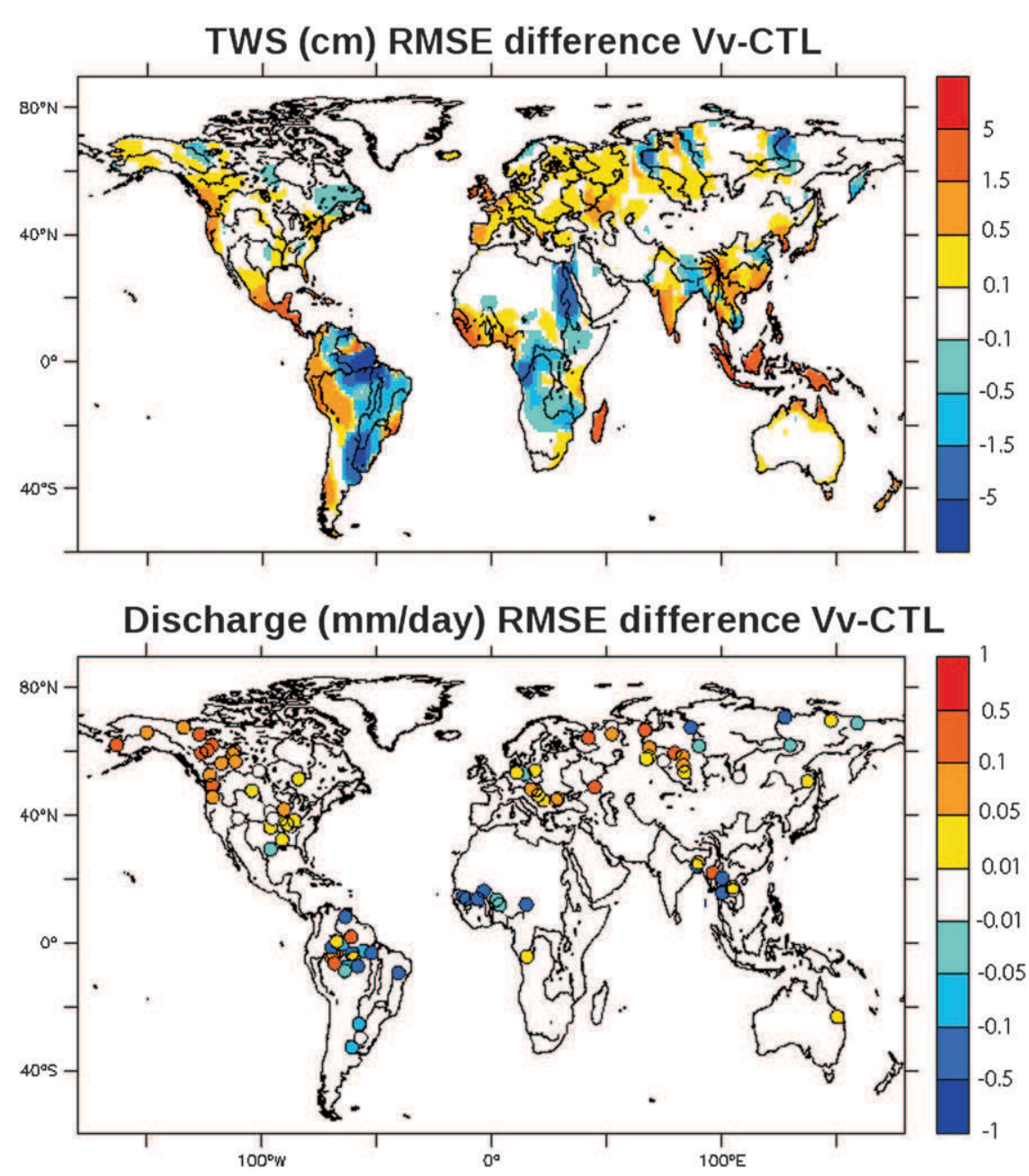

FIG. 3. Statistical comparison between the Vv and CTL experiments using the RMSE criteria. (top) TWS and (bottom) discharge signals are shown over the globe and at each gauging station, respectively.

width value, and $W_{\text {mouth }}(\mathrm{m})$ is the width of the mouth in each basin of the TRIP network.

\section{Results: New TRIP versus control}

In this section, the new TRIP is compared to the control experiment from Part I. Figure 3 shows a statistical comparison to TWS GRACE estimates and discharge measurements in terms of root-mean-square error (RMSE) difference. For TWS, the Vv simulation decreases the RMSE over an important part of South America, eastern and central Africa, and near the mouth of Siberian basins. Over Europe, North America, and South Asia, the RMSE is generally increased. The discharge scores at each gauging station show the same behavior as TWS.

Figure 4 compares simulated TWS and GRACE basinaveraged annual cycles and monthly anomalies over the largest river basins. The temporal correlation $r$ and
RMSE given on the annual cycle panels are calculated over the whole GRACE period. Except for boreal basins, this figure shows that the combination of the variable velocity and the groundwater parameterization has only a slight effect on the simulated TWS, which, in general terms, acts to slightly improve the simulation of tropical basins (Amazon, Parana, Mekong, Ganges, and Congo). This slight difference between CTL and Vv is explained by the competition between the flow velocity and the groundwater. At basin scale, the discharge into the ocean is generally accelerated when a variable flow velocity is used and therefore the quantity of water stored in the river is reduced while the presence of a groundwater reservoir increases the basin water storage. As will be shown in the next section, an increase in flow velocity implies a decrease of the TWS signal amplitude while an increase in the groundwater time delay factor leads to larger amplitude. Boreal basins (Mckenzie, Ob, Yenisey, 

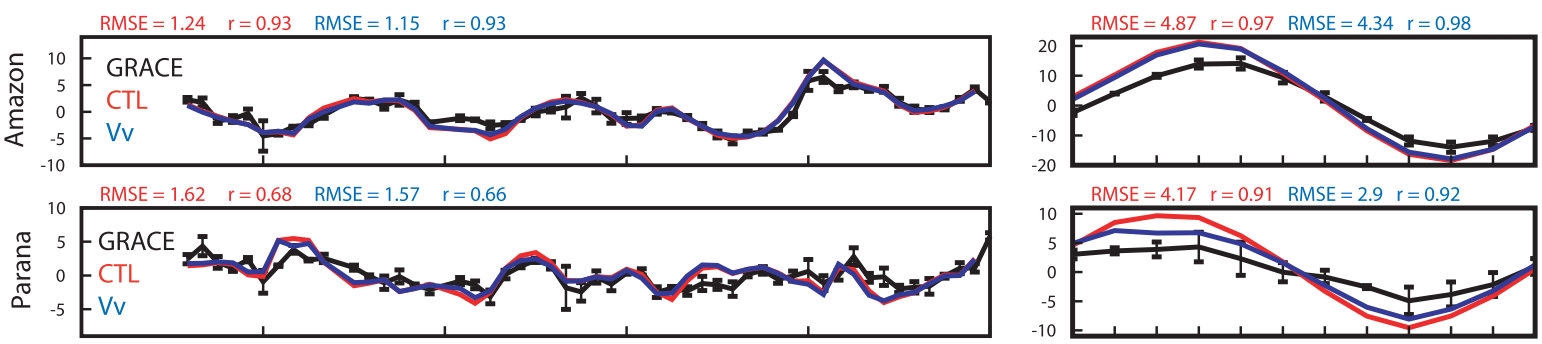

RMSE $=4.17 \quad r=0.91 \quad$ RMSE $=2.9 \quad r=0.92$

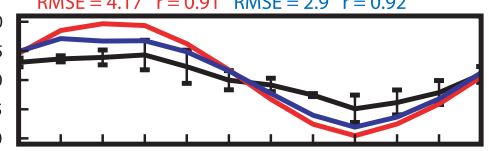

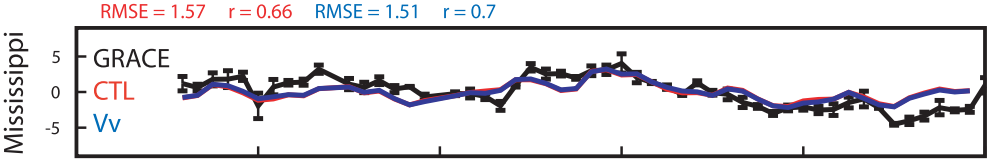

RMSE $=2.58 \quad r=0.84 \quad$ RMSE $=2.63 \quad r=0.82$

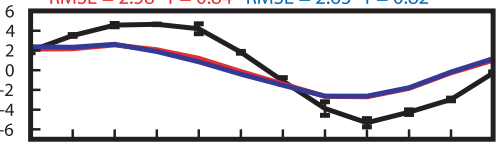

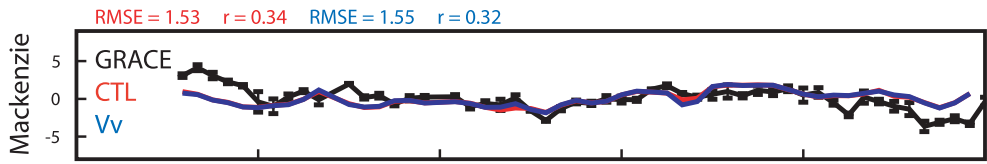

RMSE $=1.96 \quad r=0.87 \quad \operatorname{RMSE}=2.3 \quad r=0.82$

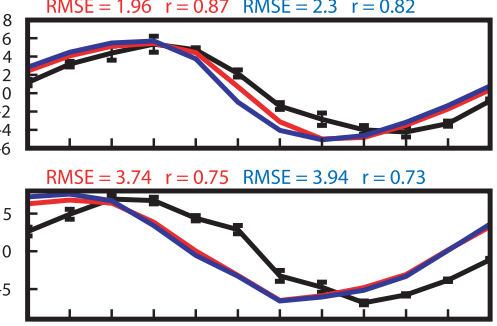

RMSE $=1.42 \quad r=0.95 \quad$ RMSE $=1.87 \quad r=0.91$
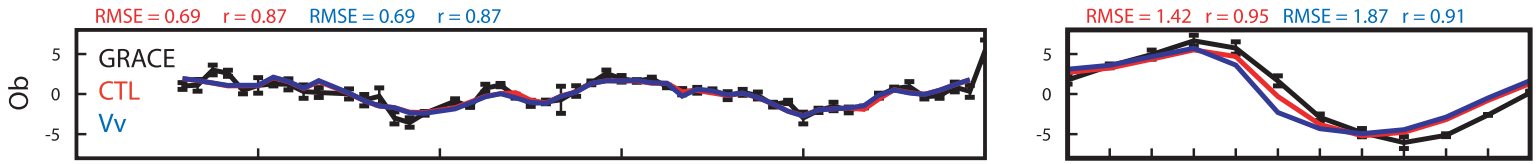

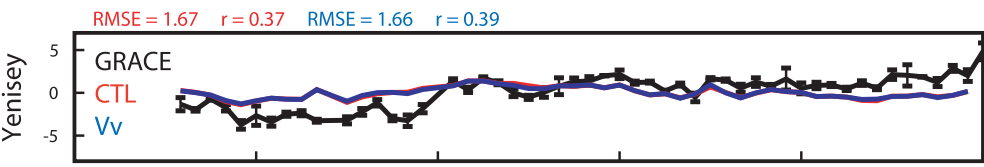

$\operatorname{RMSE}=2.05 \quad r=0.86 \quad \operatorname{RMSE}=2.21 \quad r=0.83$

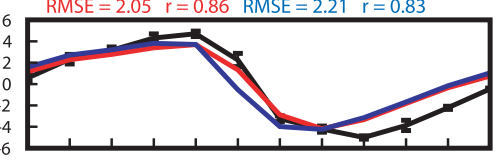

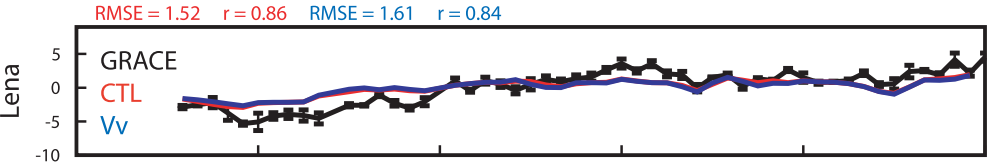

RMSE $=2.71 \quad r=0.85 \quad$ RMSE $=2.73 \quad r=0.79$

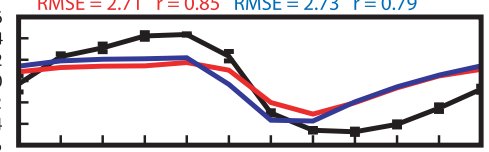

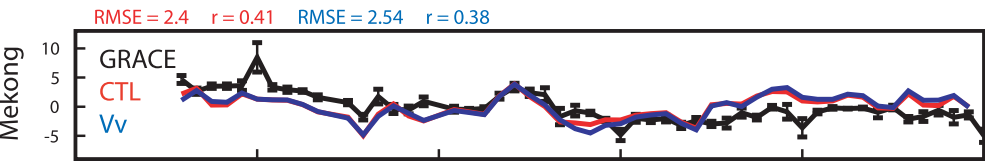

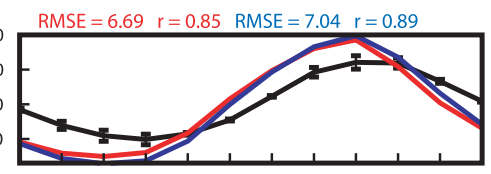

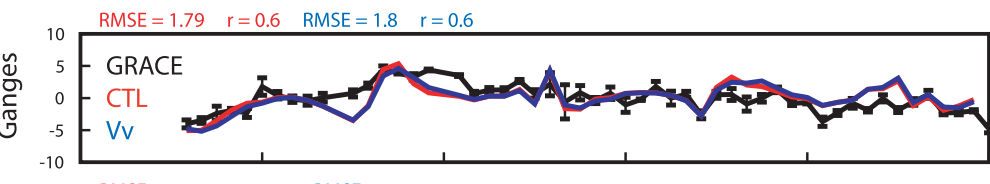

RMSE $=3.81 \quad r=0.91 \quad$ RMSE $=3.65 \quad r=0.95$

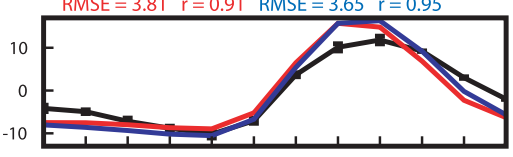

RMSE $=4.31 \quad r=0.63 \quad$ RMSE $=4.18 \quad r=0.62$
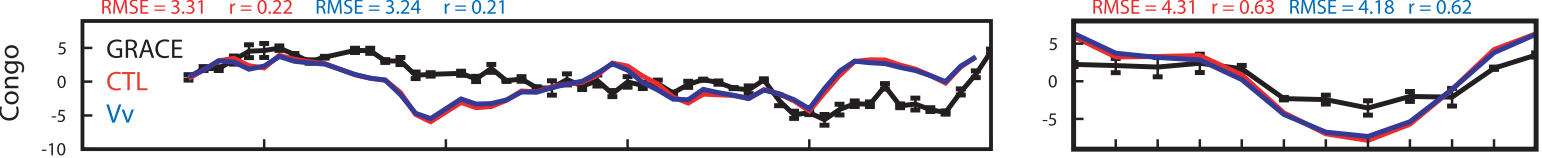

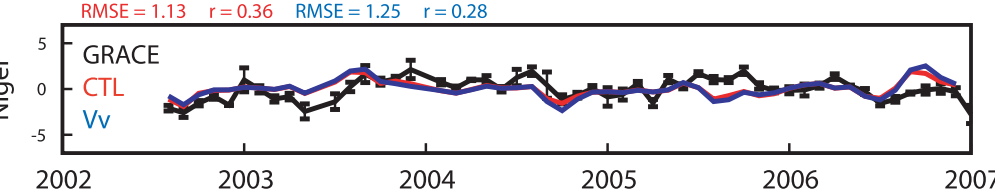

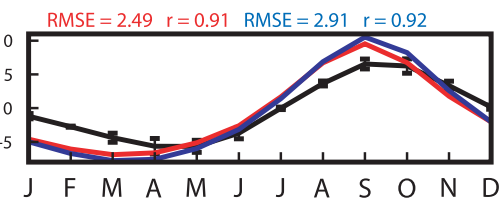

FIG. 4. Basin-scale comparison between each experiment and GRACE for (right) TWS ( $\mathrm{cm}$ ) mean annual cycles and (left) monthly anomalies. Here Vv is in blue, CTL in red, and GRACE in black. Note that RMSE and $r$ shown above the panels at right are calculated over the whole GRACE period. 

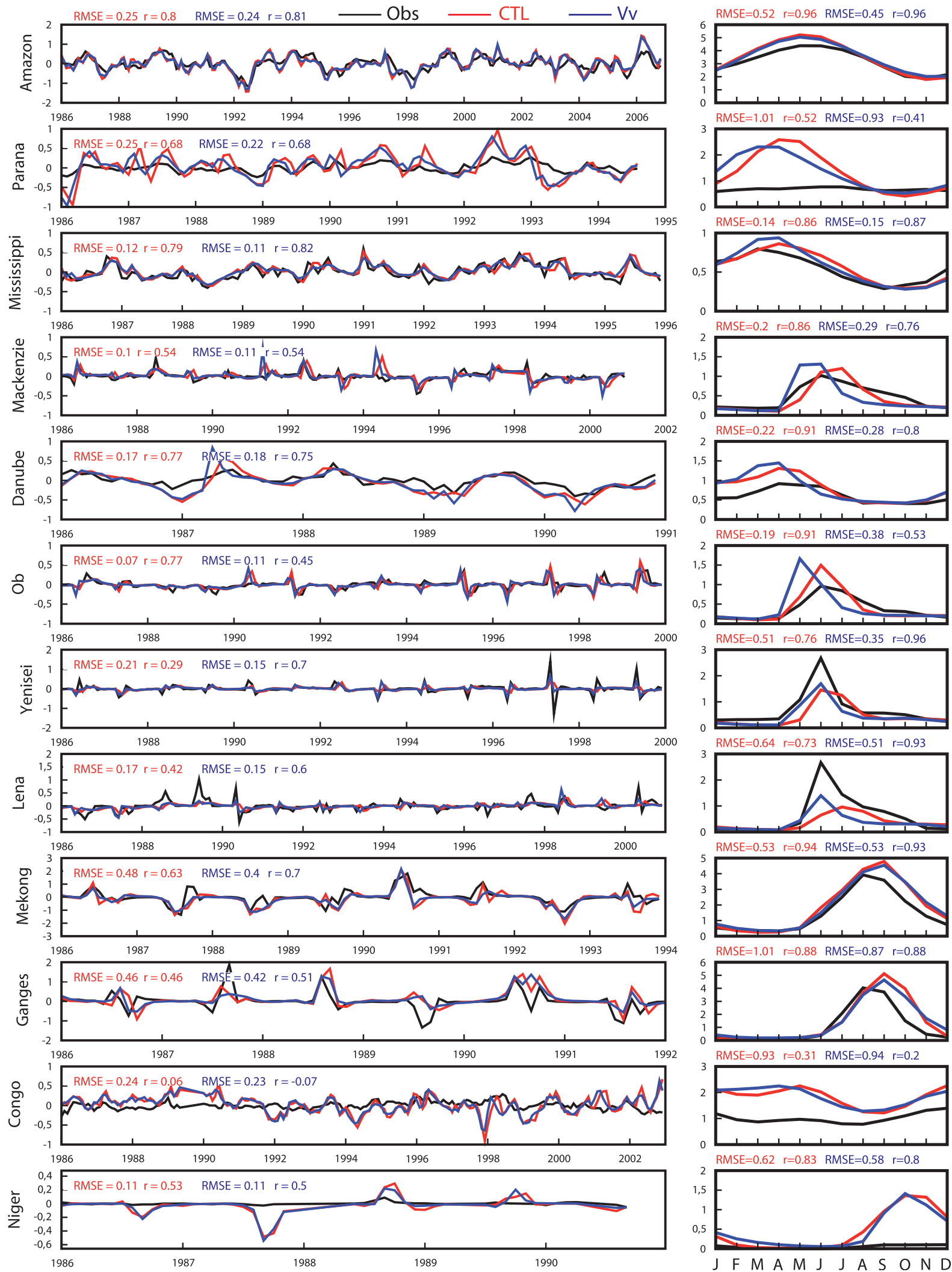

FIG. 5. Basin-scale comparisons between each experiment and in situ measurements for (right) discharge $\left(\mathrm{mm} \mathrm{day}^{-1}\right) \mathrm{mean}$ annual cycles and (left) monthly anomalies. Black curve corresponds to in situ measurements; other notations are the same as in Fig. 4. 


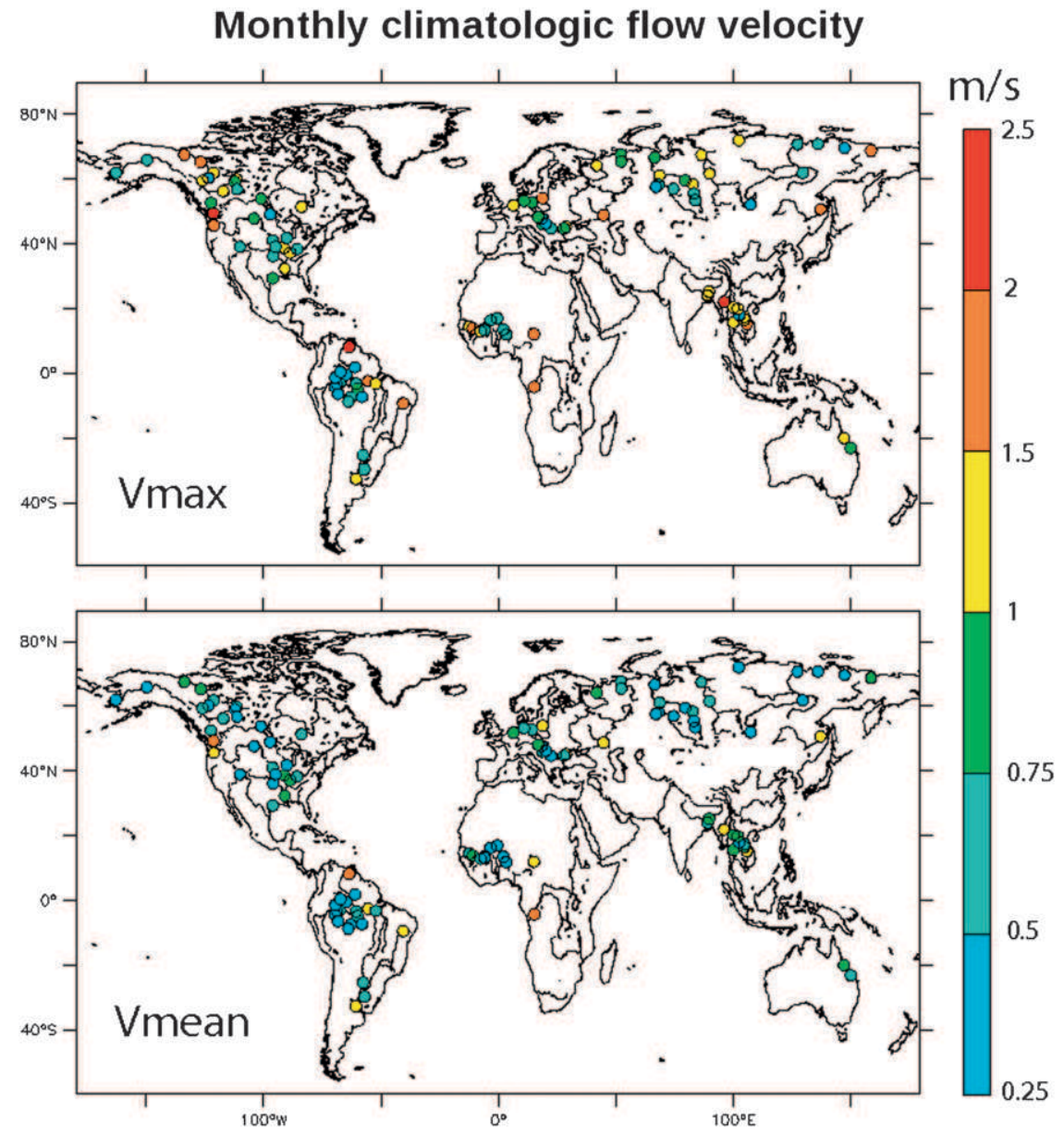

FIG. 6. Monthly climatologic (top) maximum and (bottom) mean flow velocity $\left(\mathrm{m} \mathrm{s}^{-1}\right.$ ) simulated by the $\mathrm{Vv}$ experiment at each gauging station.

Lena) show greater flow velocity effects on the TWS annual cycles, and a slight lag appears between simulation and GRACE. Analysis of the simulated river discharges and flow velocity allows this result to be better understood.

Figure 5 compares discharge simulations to observations at the downstream stations of the same basins as in Fig. 4. Annual cycles or discharge scores are generally well simulated by both simulations over the tropical and temperate regions; the largest difference appears over high-latitude basins. For example, maximum annual peaks of discharges simulated by $\mathrm{Vv}$ may appear one month earlier than CTL. The main cause is linked to flow velocity. Figure 6 shows the monthly climatologic mean and maximum flow velocity simulated by $\mathrm{Vv}$ at each gauging station. Whereas the mean velocities are generally around $0.5 \mathrm{~m} \mathrm{~s}^{-1}$ (close to CTL), the maximum velocities are generally larger but usually more reasonable $\left(0.5-2 \mathrm{~m} \mathrm{~s}^{-1}\right)$. As already mentioned, this flow velocity effect can be also found on the simulated TWS signal over boreal basins (Fig. 4). CTL shows a slight lag between simulated and estimated TWS and the use of a variable flow velocity increases this lag. This behavior is clearly in relation to the $\mathrm{Vv}$ earlier springtime peak of discharges than to CTL (Fig. 5). Fast snowmelt leads to a drastic increase in river mass storage and in flow velocity in May during fewer than 20 days. This drastic increase in flow velocity implies an acceleration of river discharges into the ocean and thus accelerates the seasonal transition between high and low TWS signal.

Kilmjaninov (2007) has shown that, over the downstream part of the Lena River, the maximum flow velocities are close to $1.5 \mathrm{~m} \mathrm{~s}^{-1}$ on a daily time scale. This maximum is reached during May after the snowmelt period, which is very strongly correlated with the springtime peak of discharges. The timing of this maximum simulated by $\mathrm{Vv}$ over the same region is realistic and can be shown on the simulated springtime peak of discharges, while CTL simulates a maximum velocity one month later (June). 


\section{TWS (cm) sensitivity experiment to the groundwater delay factor}

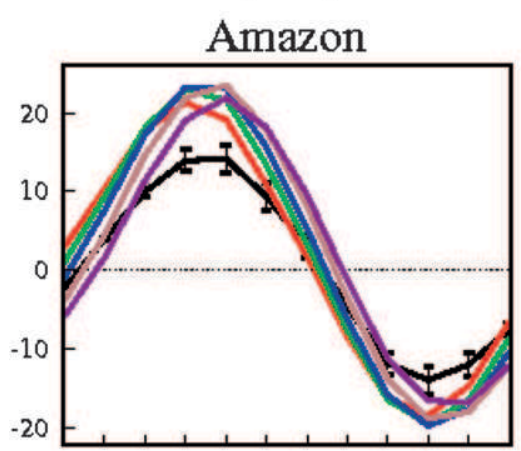

Danube

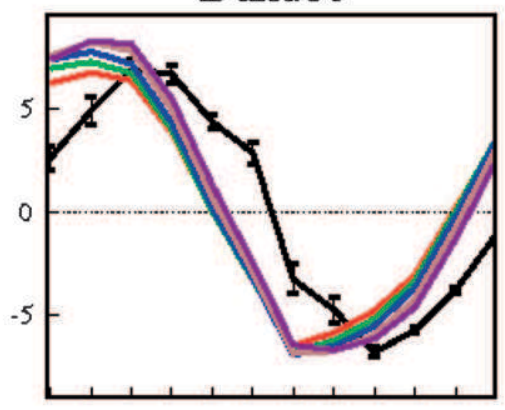

Congo

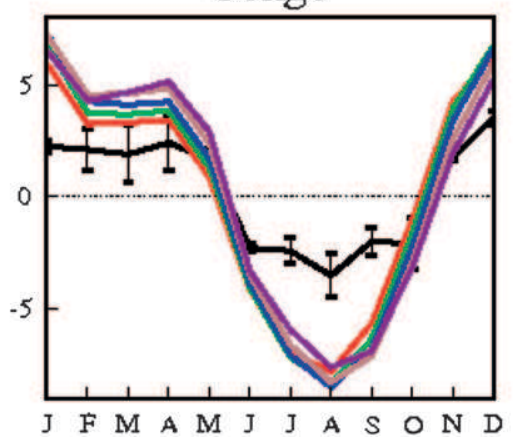

Parana

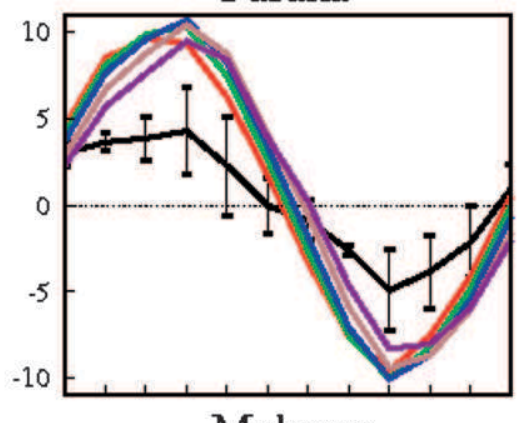

Mekong

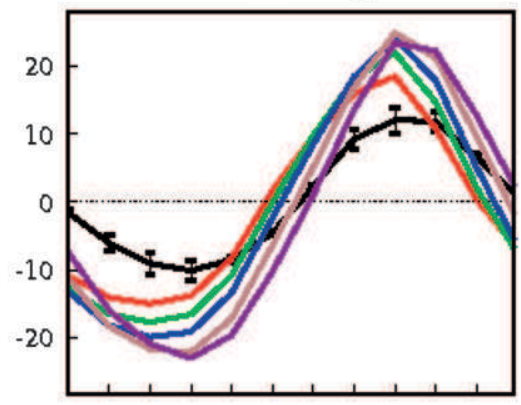

Niger

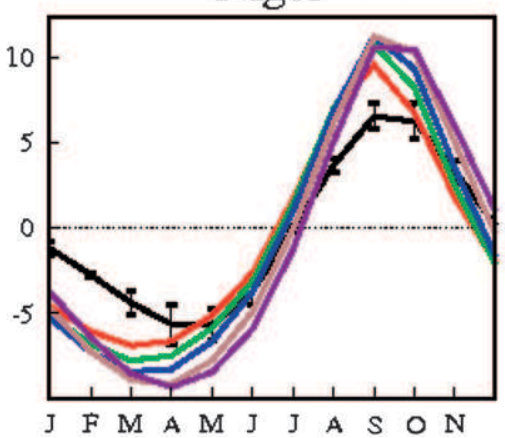

Mississippi

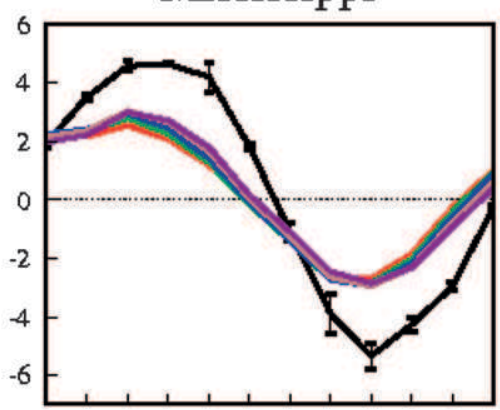

Ganges

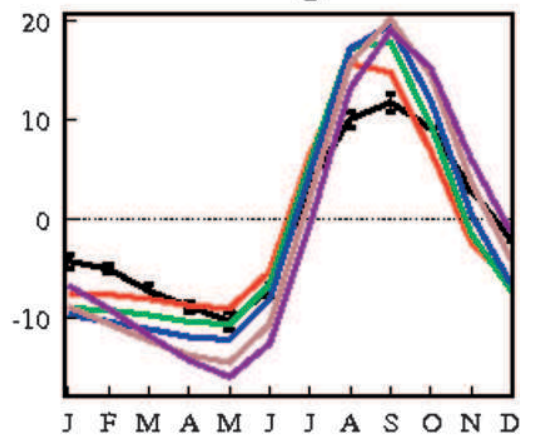

FIG. 7. Mean annual cycle comparison between the five sensitivity experiments to the groundwater delay factor given in Table 1 , and the GRACE TWS estimate (black curve) for the same basins as in section 4. Exception is made for boreal basins where groundwater processes are not simulated.

Figure 6 shows that the $\mathrm{Vv}$ climatologic monthly maximum velocity (around $0.7 \mathrm{~m} \mathrm{~s}^{-1}$ ) is larger than the CTL constant velocity $\left(0.5 \mathrm{~m} \mathrm{~s}^{-1}\right)$ but still smaller than the daily observations $\left(1.5 \mathrm{~m} \mathrm{~s}^{-1}\right)$ by Kilmjaninov (2007). On a daily time scale, over the same domain and over the same period as in Kilmjaninov (2007), the maximum velocity simulated by $\mathrm{Vv}$ reaches $1 \mathrm{~m} \mathrm{~s}^{-1}$. This difference is explained by an underestimation in precipitation forcing over east Siberia (Decharme and Douville 2006) because flow velocities are directly proportional to river mass [Eq. (4)]. This fact is confirmed by the simulated discharges, which are underestimated by approximately $40 \%$ over the same region.

\section{Sensitivity study}

While the influence of the flow velocity is clearly seen over high-latitude basins where groundwater processes have no effect, it is difficult to examine the deep flow contribution to the simulated TWS and discharge uncertainties over other regions. As stated previously, in this subsection a study of sensitivity to $\tau$ was performed using a constant flow velocity (Table 1). Figure 7 compares the five simulated annual cycles with the GRACE TWS estimates for the same basins as in section 4 except for the boreal basins, where groundwater processes are not represented. Figure 8 shows the same comparison 


\section{Discharge ( $\mathrm{mm} /$ day) sensitivity experiment to the groundwater delay factor}
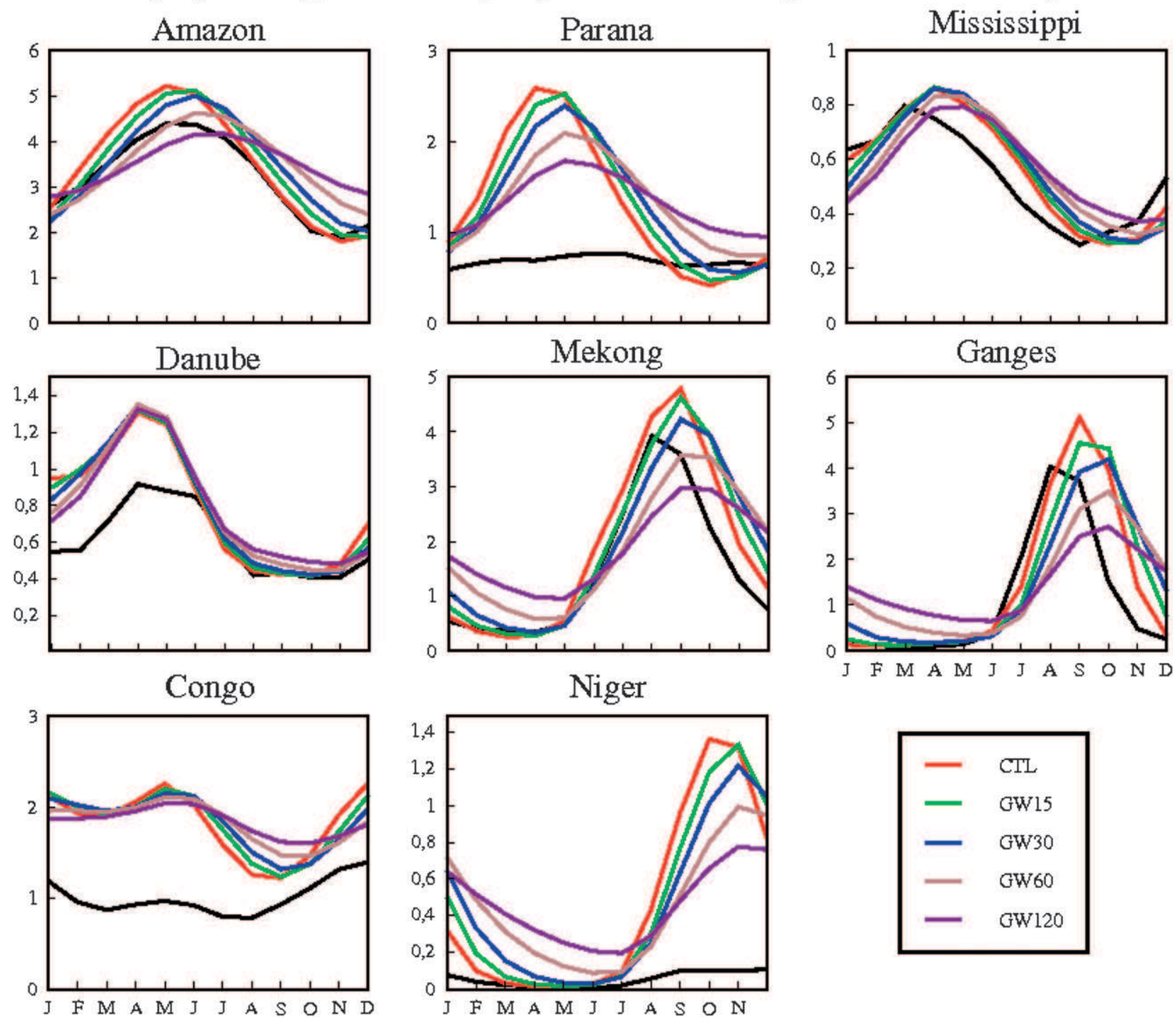

FIG. 8. As in Fig. 7 but for discharge measurements. Black curve corresponds to discharge measurements; other notations are the same as in Fig. 7.

but for river discharge at each downstream station. Over tropical basins, the spread among all annual cycles appears large, especially on simulated river discharges. This effect is less marked over temperate basins. As mentioned in section 4 , the groundwater time delay factor acts to increase the residence time of water on the downstream reservoir and consequently acts on TWS and discharge seasonal amplitudes and phasing. A larger $\tau$ increases (decreases) the TWS (discharge seasonal amplitude) and delays the peak of annual discharge.

Figure 9 attempts to resume this sensitivity study by comparing the TWS and discharge spatial distributions of time-averaged monthly standard deviation (STD) among all simulations and over all basins of the TRIP network:

$$
\mathrm{STD}=\frac{1}{N_{\mathrm{mth}}} \sum_{j=1}^{N_{\mathrm{mth}}} \sqrt{\frac{1}{N_{\text {sim }}} \sum_{i=1}^{N_{\text {sim }}}\left(\operatorname{SIM}_{i, j}-\overline{\operatorname{SIM}}_{j}\right)^{2}}
$$

where $N_{\mathrm{mth}}$ is the number of months in the simulations (equal to 240), $N_{\text {sim }}$ is the number of simulations (equal to five), SIM is the monthly simulated value for each experiment $i$, over each basin, and SIM is the average of all experiments at month $j$. To quantify the potential error due to the groundwater delay factor, STD is also related 


\section{Standard deviation between all groundwater delay factor sensitivity experiments}
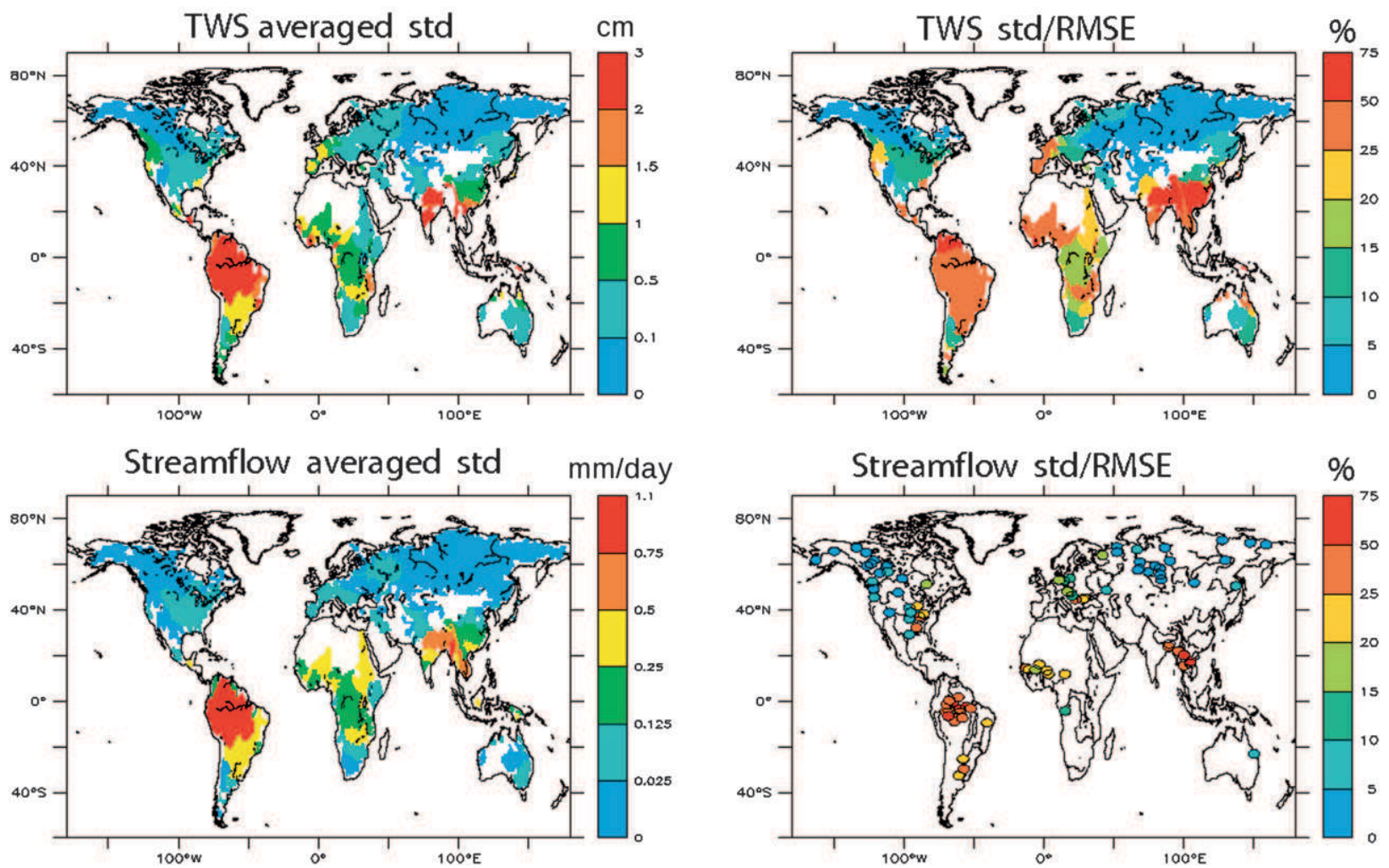

FIG. 9. Basin-scale comparison between the (top) TWS and (bottom) discharge spatial distributions of (left) time-averaged monthly STD between all groundwater delay factor sensitivity experiments given in Table 1. (right) The ratio of STD to the CTL RMSE from Part I is given in percent. For discharges, this ratio is calculated at each gauging station.

to the error in the CTL simulation using the ratio to CTL RMSE from Part I. For discharges, the ratio of std to RMSE is only computed at each gauging station. This figure confirms that uncertainties due to groundwater for simulating TWS and discharges are located over tropical basins and, to a lesser extent, over temperate latitudes. Compared to CTL RMSE, this uncertainty could be potentially significant on the ISBA-TRIP simulation errors.

Regarding the sensitivity of the simulations to the flow velocity with the $\tau$ groundwater time delay factor fixed at 30 days, Fig. 10 compares the five simulations (Table 1 ) with the GRACE TWS estimate for the same basin as in Fig. 5 while Fig. 11 shows the same comparison but for river discharge at each gauged station. Globally, the spread among all annual cycles appears significant for both TWS and discharge signals. The flow velocity seems to affect both the TWS and discharge phasing more than the seasonal amplitude. It is interesting to note that the gap between slow velocity simulations (V0.25 and V0.5) is drastically larger than between other simulations (V1 and V1.5). A slow river velocity favors runoff storage in the river reservoir to the detriment of flow to the downstream grid cell. The consequence is to delay the TWS and discharge signals compared to faster flow velocity simulations in which this "flow control by storage" is less important. As discussed in section 4 and in opposition to the groundwater effect, a larger flow velocity accelerates the water discharge to the ocean to the detriment of river storage.

Figure 12 attempts to resume this sensitivity study by comparing the TWS and discharge spatial distributions using the STD criteria [Eq. (5)] as in Fig. 9. Over tropical and temperate basins, uncertainties linked to flow velocity are generally comparable to uncertainties due to the groundwater delay factor. Figure 12 confirms also that the effect of flow velocity is significant over boreal regions. In the same way as for groundwater sensibility, the STD to RMSE ratio points out that this uncertainty could potentially contribute significantly to the ISBATRIP simulation errors.

Focusing on the simulated velocity, Figs. 10 and 11 seem to confirm that flow velocities lower than $0.5 \mathrm{~m} \mathrm{~s}^{-1}$ are not realistic and are certainly closer to $0.5-1 \mathrm{~m} \mathrm{~s}^{-1}$ on global average. This fact seems to be especially true for boreal regions in May, where maximum velocity can be higher than $1-1.5 \mathrm{~m} \mathrm{~s}^{-1}$. The $0.5-1 \mathrm{~m} \mathrm{~s}^{-1}$ velocities 
TWS (cm) sensitivity experiment to the flow velocity
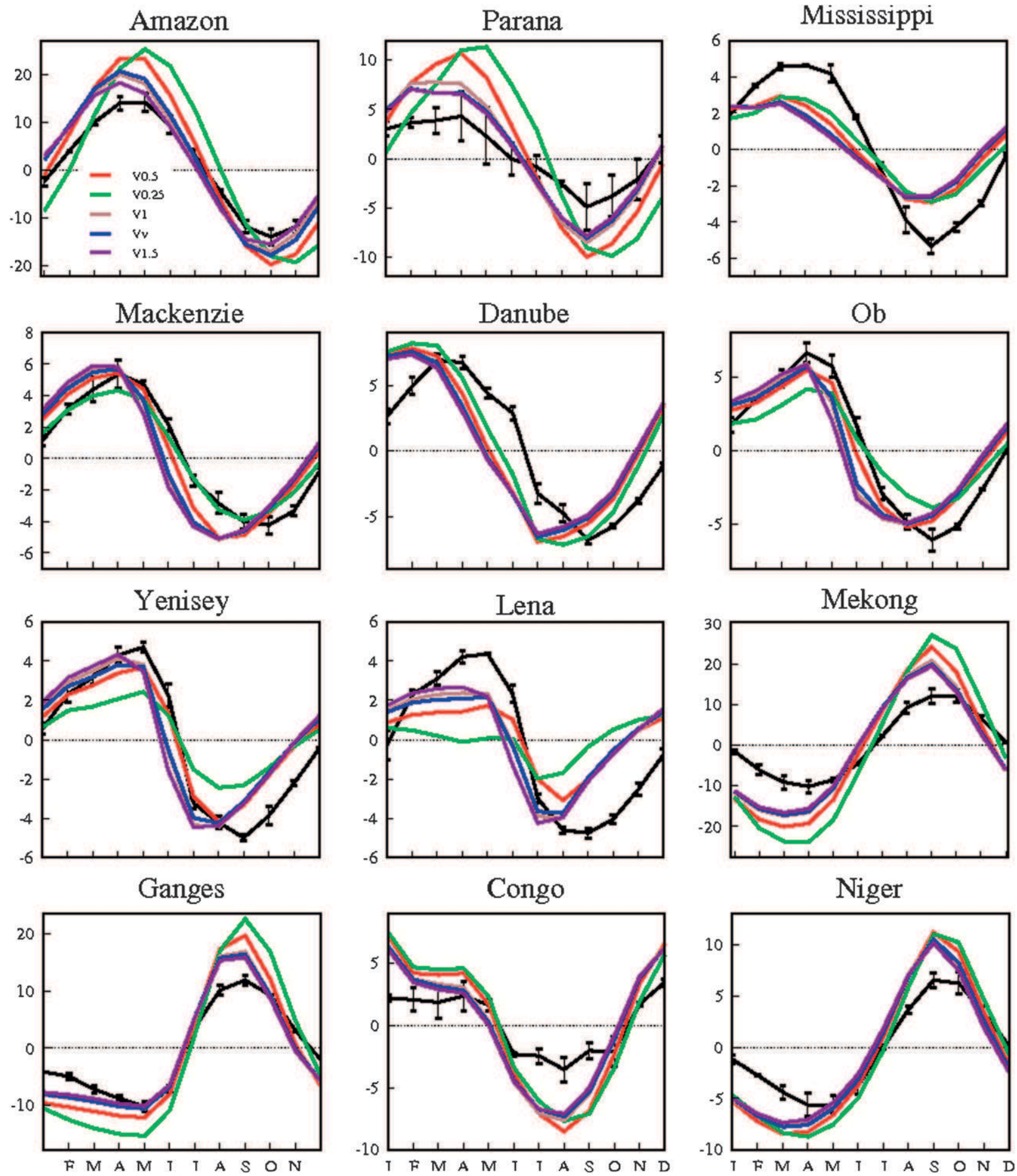

FIG. 10. Mean annual cycle comparison as in Fig. 7 but for the sensitivity experiments to the flow velocity given in Table 1 . The same basins as in section 4 are shown. 
Discharge ( $\mathrm{mm} /$ day) sensitivity experiment to the flow velocity
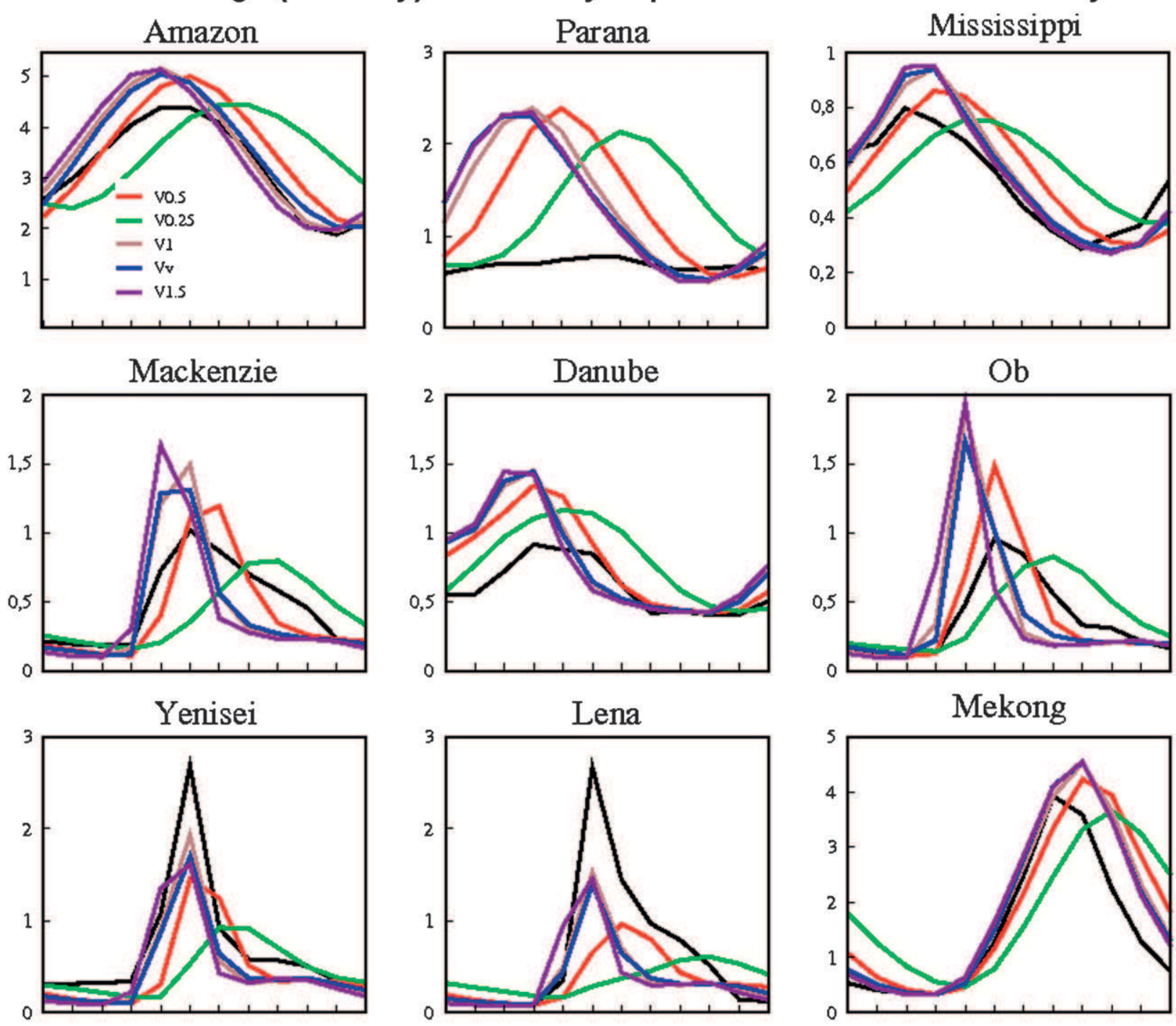

Ganges
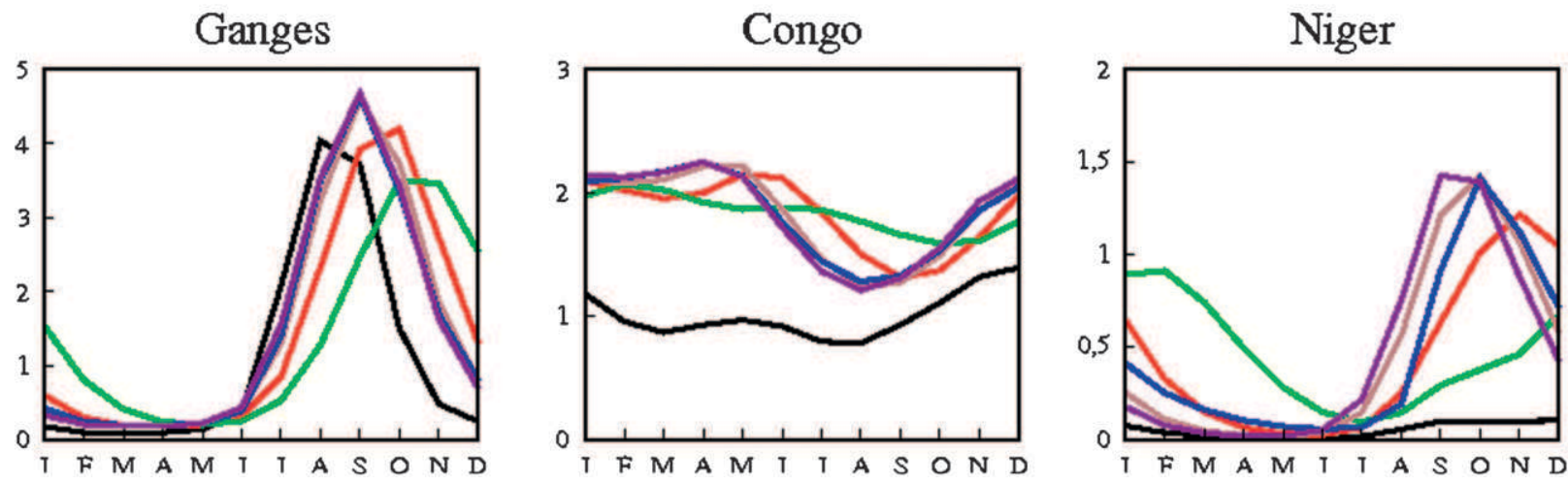

FIG. 11. Mean annual cycle comparison as in Fig. 8 but for the sensitivity experiments to the flow velocity given in Table 1. 


\section{Standard deviation between all flow velocity sensitivity experiments}
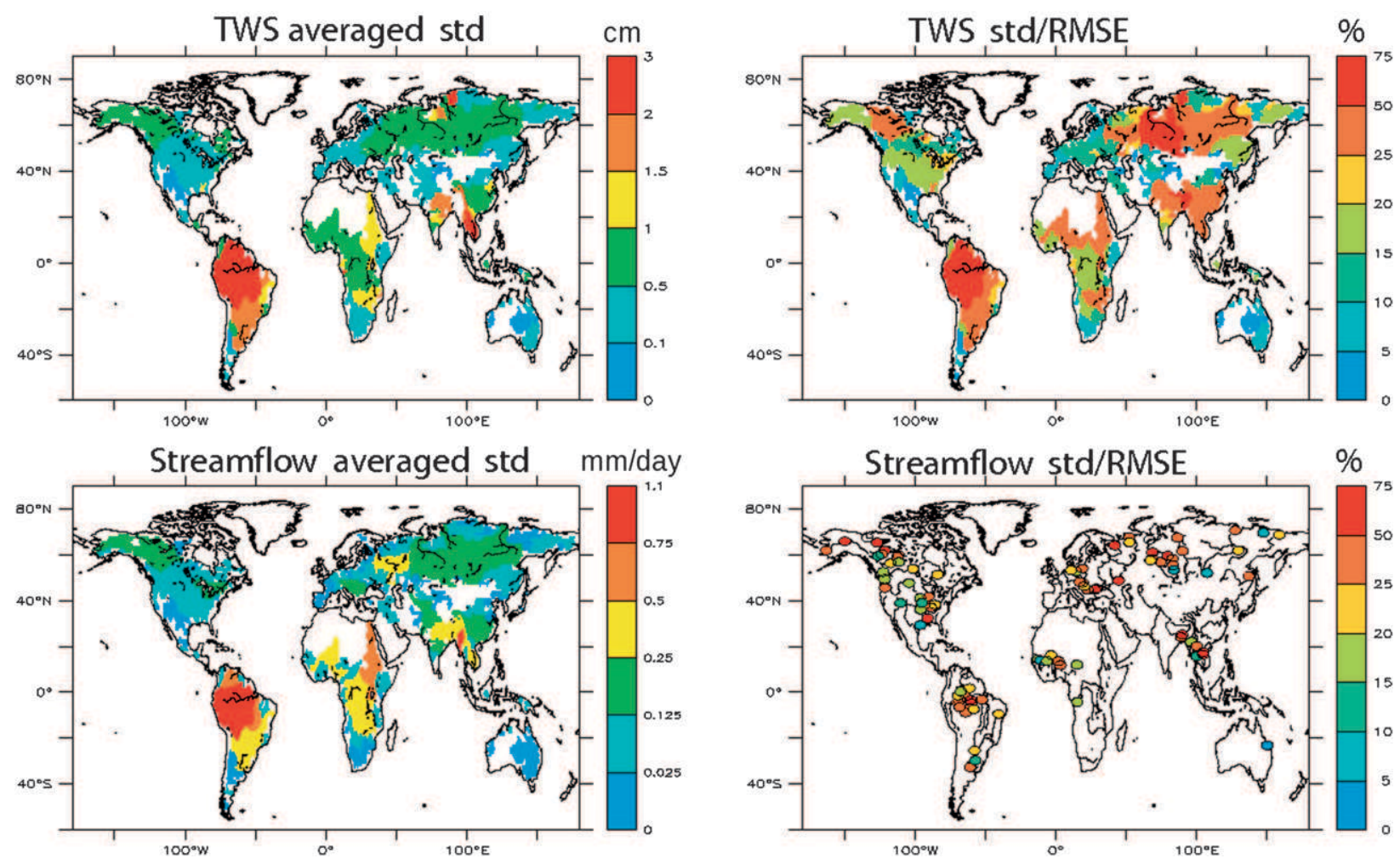

FIG. 12. As in Fig. 9, but for the flow velocity sensitivity experiments.

give appreciable results, especially in simulating river discharge, except over the $\mathrm{Ob}$ and Mackenzie Rivers (Fig. 5). Over these basins, large floods take place in May when the mass of water in the river increases. Consequently, a significant part of the water is not available for flowing, and flooding limits the streamflow velocity compared to basins with more negligible floodplain processes (Yenisey, Lena). For example, over the $\mathrm{Ob}$, large floods appear after the snow melting period. The flood plains can cover $10 \%$ of the basin area, and the flow velocity is generally limited to $0.5 \mathrm{~m} . \mathrm{s}^{-1}$ because of the significant water storage induced by these large flood plains (Kouraev et al. 2004). Over other regions, the same process is observed in South America and West Africa, while irrigation and/or dams certainly have a larger effect over temperate regions and South Asia (Hanasaki et al. 2006; Adam et al. 2007; Decharme et al. 2008).

\section{Conclusions}

The present study focuses on the assessment of uncertainties in global river routing modeling due to groundwater storage and flow velocity, using the TRIP RRM. For this purpose, a simple groundwater reservoir and a variable streamflow velocity are added to TRIP following Arora and Boer (1999). This groundwater parameterization is not dynamic and only takes into account the time delay groundwater flow contribution to the river streamflow. The variable velocity is introduced using the Manning formula. The previous and the new TRIP simulations, using the same input runoff from Part I, are then compared, and two studies of sensitivity to the groundwater time delay factor and to the flow velocity are performed. The evaluation is made by comparison to TWS GRACE estimates and in situ discharge measurements.

Comparison between the CTL (previous TRIP version) and the $\mathrm{Vv}$ (variable flow velocity and groundwater storage) experiment shows that TWS and discharge signals are only slightly affected over nonboreal basins by the use of a variable flow velocity and a time delay groundwater flow contribution. The discharges to the ocean are generally accelerated by the use of a variable flow velocity while the residence time of water storage is increased because of the groundwater time delay factor. This competition between flow velocity and groundwater explains the slight difference observed in section 4 between the CTL and Vv, except over Arctic basins where groundwater is not present and where the spring-summer flow velocity is generally higher than $0.5 \mathrm{~m} \mathrm{~s}^{-1}$. However, 
over boreal regions, a significant difference appears compared to CTL where a nonnegligible lag is observed relative to the GRACE signal and to some discharges. Over the $\mathrm{Ob}$ and the Mackenzie, the main cause is the simulation of an excessive flow velocity.

The comparison to GRACE estimates and discharge measurements given in section 4 shows that discharge scores are more affected than TWS scores by the CTL in $\mathrm{Vv}$ experiments. As in Part I, it could seem that the GRACE data do not add new information to the discharge comparisons. Nevertheless, the large sensitivities on both the simulated TWS and discharge signals shown in section 5 emphasizes that the combined use of GRACE and discharge data to evaluate RRMs processes can be useful, at least to consolidate the evaluation by discharge comparison only.

The sensitivity experiments given in section 5 point out that the effect of the flow velocity and of the groundwater time delay factor on the ISBA-TRIP simulation are potentially large. Sensitivity to the groundwater time delay factor is especially important over South America, Africa, South Asia, western Europe, and a part of North America for both TWS and discharge comparisons. To a first order, a simple implementation of a groundwater reservoir following Arora and Boer (1999) appears interesting for using TWS and/or discharge in model evaluation. The present results stress that a time delay factor of the order of 30-60 days is generally suitable for global simulation. This range is compatible with the conclusions of Brutsaert (2008), who estimates a time delay factor for large basins of the order of $45 \pm 15$ days. Nevertheless, the present simple groundwater representation is certainly less suitable for climate applications like future climate projections. Over tropical and temperate basins, groundwater acts as a boundary condition for land surface moisture and then evapotranspiration, especially during the dry season. It appears important to include a more physically based approach accounting for groundwater dynamics (storage and redistribution over the whole basin) and the possible reevaporation of the deep water via diffusive exchanges with the land surface (Fan et al. 2007; MiguezMacho et al. 2007) in CHS used for present and future climate applications. In addition, direct exchanges between the groundwater and the stream reservoir could have an effect on variations in stream mass and then on river flow velocity, especially if Manning's formula is used.

Sensitivity to flow velocity is particularly large over the entire globe, as shown in section 5. Simulating a realistic streamflow velocity appears as a key process at global scale. Using a constant flow velocity is useful for simple global hydrological applications. While over tropical and temperate basins, a value of $0.5 \mathrm{~m} \mathrm{~s}^{-1}$ seems to be acceptable; a value close to $1 \mathrm{~m} \mathrm{~s}^{-1}$ is more suitable over high latitudes. Nevertheless, the tuning of this velocity basin by basin on a global scale appears complicated and is not recommended for future climate applications. The results of this study show that Manning's formula via the approach of Arora and Boer (1999) could provide an interesting alternative. Although special attention must be paid to both the river slope and to the Manning friction factor computations, this parameterization enables acceptable variation in flow velocity to be simulated on a global scale.

Acknowledgments. The authors wish to thank the GRACE, GRDC, R-ArcticNET, and HYBAM sampling teams for their field data collection effort. This work is supported by the CYMENT project of the RTRA STAE Toulouse, the Centre National de Recherches Météorologique of Méteo-France and the Centre National de la Recharche Scientifique of the French research ministry, and the IMPACT BOREAL project of the French Agence Nationale de la Recherche. Thanks are also due to the anonymous reviewers for their constructive comments.

\section{REFERENCES}

Adam, J. C., I. Haddeland, F. Su, and D. P. Lettenmaier, 2007: Simulation of reservoir influenced on annual and seasonal streamflow changes for the Lena, Yenisei, and $\mathrm{Ob}$ ' rivers. J. Geophys. Res., 112, D24114, doi:10.1029/2007JD008525.

Alkama, R., and Coauthors, 2010: Global evaluation of the ISBATRIP continental hydrological system. Part I: Comparison to GRACE terrestrial water storage estimates and in situ river discharges. J. Hydrometeor., 11, 583-600.

Arora, V. K., and G. J. Boer, 1999: A variable velocity flow routing algorithm for GCMs. J. Geophys. Res., 104, 30965 30979.

_ F. H. S. Chiew, and R. B. Grayson, 1999: A river flow routing scheme for general circulation models. J. Geophys. Res., 104, 14 347-14 357.

Broecker, W. S., T.-H. Peng, J. Jouzel, and G. L. Russell, 1990: The magnitude of global fresh-water transports of importance to ocean circulation. Climate Dyn., 4, 73-79.

Brown, J., O. J. Ferrians Jr., J. A. Heginbottom, and E. S. Melnikov, 1998: Circum-arctic map of permafrost and ground ice conditions. National Snow and Ice Data Center/World Data Center for Glaciology, Boulder, CO, digital media. [Available online at http://nsidc.org/data/docs/fgdc/ggd318_map_circumarctic/index. html.]

Brutsaert, W., 2008: Long-term groundwater storage trends estimated from streamflow records: Climatic perspective. Water Resour. Res., 44, W02409, doi:10.1029/2007WR006518.

Cogley, J. G., 2003: GGHYDRO - Global Hydrographic Data, Release 2.3. Trent Tech. Note 2003-1, Department of Geography, Trent University, Peterborough, Canada, 11 pp. [Available online at http://people.trentu.ca/ gcogley/glaciology/index.htm.]

Decharme, B., and H. Douville, 2006: Uncertainties in the GSWP-2 precipitation forcing and their impacts on regional and global hydrological simulations. Climate Dyn., 27, 695-713. 
, C. Prigent, F. Papa, and F. Aires, 2008: A new river flooding scheme for global climate applications: Off-line evaluation over South America. J. Geophys. Res., 113, D11110, doi:10.1029/2007JD009376.

Fan, Y., G. Miguez-Macho, C. P. Weaver, R. Walko, and A. Robock, 2007: Incorporating water table dynamics in climate modeling: 1 . Water table observations and equilibrium water table simulations. J. Geophys. Res., 112, D10125, doi:10.1029/2006JD008111.

Hanasaki, N., S. Kanae, and T. Oki, 2006: A reservoir operation scheme for global river routing models. J. Hydrol., 327, 22-41.

Kilmjaninov, V., 2007: Hydrological conditions for actions on prevention of ice flooding on the Lena River. Extreme Hydrological Events: New Concepts for Security, O. F. Vasiliev et al., Eds., NATO Science Series, Vol. 78, 279-284.

Kim, H., P. J.-F. Yeh, T. Oki, and S. Kanae, 2009: Role of rivers in the seasonal variations of terrestrial water storage over global basins. Geophys. Res. Lett., 36, L17402, doi:10.1029/2009GL039006.

Kouraev, A., E. A. Zakharova, O. Samain, N. M. Mognard-Campbell, and A. Cazenave, 2004: Ob' river discharge from TOPEX/
Poseidon satellite altimetry (1992-2002). Remote Sens. Environ., 93, 238-245.

Lucas-Picher, P., V. K. Arora, D. Caya, and R. Laprise, 2003: Implementation of a large-scale variable velocity flow routing algorithm in the Canadian Regional Climate Model (CRCM). Atmos.-Ocean, 41, 139-153.

Miguez-Macho, G., Y. Fan, C. P. Weaver, R. Walko, and A. Robock, 2007: Incorporating water table dynamics in climate modeling: 2. Formulation, validation, and soil moisture simulation. J. Geophys. Res., 112, D13108, doi:10.1029/ 2006JD008112.

Oki, T., and Y. C. Sud, 1998: Design of Total Runoff Integrating Pathways (TRIP) - A global river channel network. Earth Interactions, 2. [Available online at http://EarthInteractions.org.]

Pachauri, R. K., and A. Reisinger, Eds., 2007: Climate Change 2007: Synthesis Report. Cambridge University Press, 104 pp. [Available online at http://www.ipcc.ch.]

Sausen, R., S. Schubert, and L. Dümenil, 1994: A model of river runoff for use in coupled atmosphere-ocean models. J. Hydrol., $\mathbf{1 5 5}, 337-352$. 